Research Article

\title{
Cationic porous aromatic framework with hierarchical structure for selective, rapid and efficient removal of anionic dyes from water
}

\author{
Wenjie $\mathrm{Yu}^{1} \cdot$ Hengye $\mathrm{Li}^{2} \mathbb{D} \cdot$ Lin $\mathrm{Zhang}^{3} \cdot$ Jing $\mathrm{Liu}^{4} \cdot$ Fenying Kong ${ }^{2} \cdot$ Wei Wang $^{2,5}$
}

Received: 12 January 2020 / Accepted: 2 March 2020 / Published online: 9 March 2020

(c) Springer Nature Switzerland AG 2020

\section{Graphic abstract}

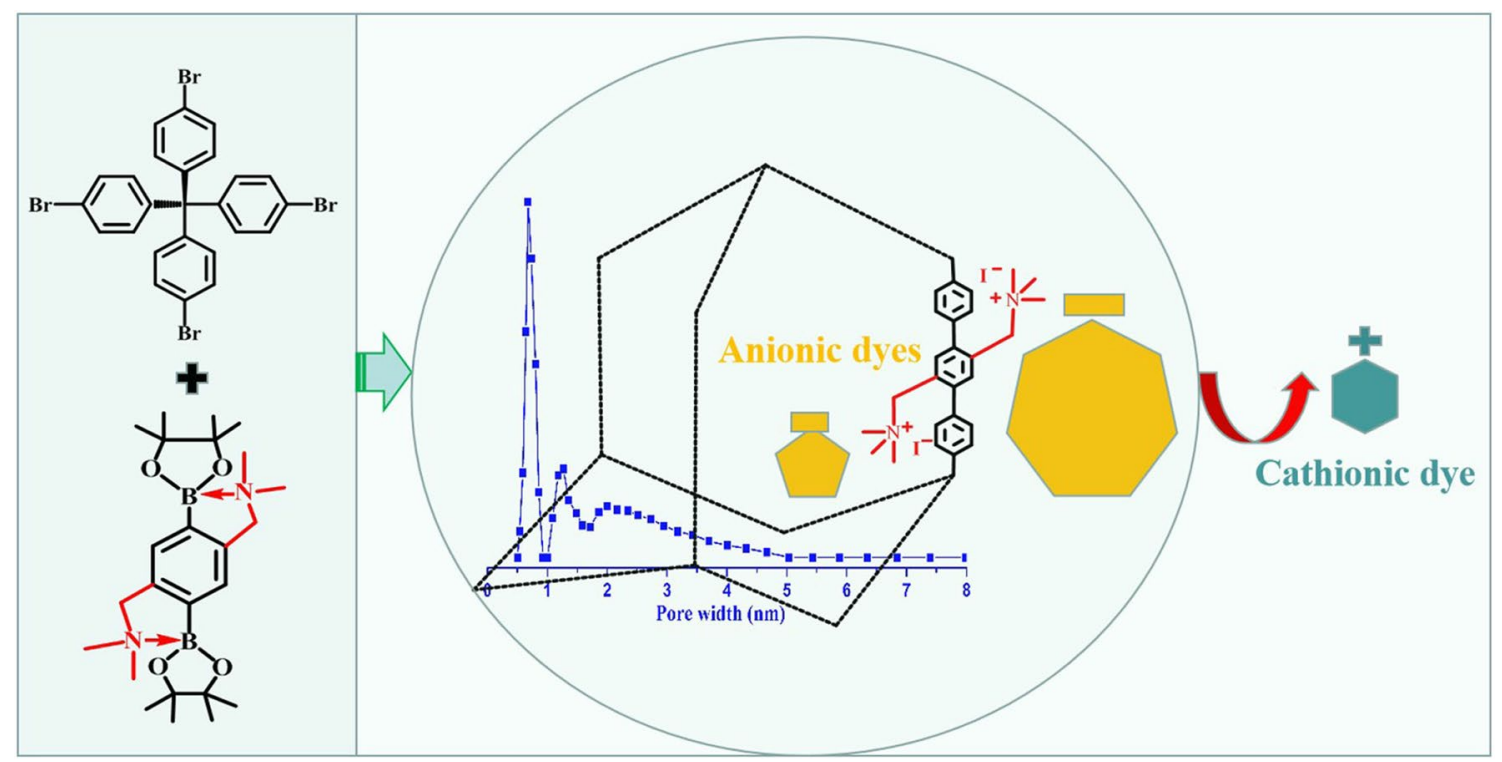

Keywords Porous aromatic frameworks · Anionic dyes · Cationic porous materials · Adsorption · Water treatment

Electronic supplementary material The online version of this article (https://doi.org/10.1007/s42452-020-2399-7) contains supplementary material, which is available to authorized users.

Hengye Li, lhy1024006@sina.com; $₫$ Lin Zhang, hbwhzl@126.com; $₫$ Wei Wang, wangw@ycit.edu.cn|'School of Chemistry and Chemical Engineering, Jiangsu University, Zhenjiang 212013, People's Republic of China. ${ }^{2}$ School of Chemistry and Chemical Engineering, Yancheng Institute of Technology, Yancheng 224002, People's Republic of China. ${ }^{3}$ Comprehensive Testing Center, Yancheng Customs, Yancheng 224002, People's Republic of China. ${ }^{4}$ School of Pharmacy, China Pharmaceutical University, Nanjing 210009, People's Republic of China. ${ }^{5}$ School of Chemistry and Chemical Engineering, Yangzhou University, Yangzhou 225002, People's Republic of China. 


\section{Introduction}

Water pollution has become a serious environmental problem worldwide. Organic dyes are among the major categories of water pollutants because of their toxicity to mankind and aquatic living organisms [1]. Adsorption is one of the most effective techniques for pollutant removal due to its low cost and simple operation [2-5] and adsorbents are the core of adsorption process [6]. Traditional adsorbents, such as Activated carbon [7], zeolites [8], porous silica [9] and clays [10], have been applied for pollutant removal. However, they have inherent drawbacks including slow adsorption rate, low selectivity, limited adsorption capacities and energy-intensive regeneration. To address these issues, adsorbents with fast adsorption kinetics, high efficiency and selectivity as well as recyclability are in urgent need.

Recently, on the basis of rational molecular design, various novel porous materials have been developed as advanced adsorbents for dyes and other kinds of pollutants removal, such as metal-organic frameworks (MOFs) [11-13], covalent organic frameworks (COFs) [14-16], porous organic polymers (POPs) [17-19] and porous aromatic frameworks (PAFs) [20-26]. It is known that high stability, proper porous structure and abundant functional groups are fundamental elements for effective adsorbents [27-29]. In this context, PAFs, such as PAF-1 [30], are a class of promising adsorbents, owing to their robust structure, permanent porosity and especially high thermal and chemical stability [31]. However, PAFs with task-specific functional groups and porosity are still limited. The introduction of functional groups into PAFs has been proved as an efficient way to achieve adsorption selectivity [24-26]. Post-modification method was initially adopted for this purpose. For example, thiol group [20, 22] and quaternary ammonium [21] were introduced into the backbone of PAF-1 through this method for metal ions capture and dye removal. However, this method faces a problem that the functional groups could not be precisely located or uniformly distributed in the post-modified PAFs [32]. To solve this problem, precursor-designed method was used to obtain functionalized PAFs using corresponding functionalized building blocks [32]. By this method, hydroxyl [26], carboxyl [31] and imidazolium [33] were introduced into PAFs. The precursor-designed method featured high loading and defined locating position of functional groups, facilitating the homogeneous distribution of functional groups in the PAFs [31, 32]. As for dyes removal, adsorbents with charged moieties have improved adsorption capacities and selectivity $[18,34,35]$. So, functionalized PAFs with homogeneous distribution of charged moieties are promising adsorbents for dyes removal.
Furthermore, pore structure also plays a crucial role to the performance of a adsorbent. The pore structure of some of the charged adsorbents is mainly composed of micropores, which are not large enough to accommodate large-sized dye, such as methyl blue $[14,17,21]$. In addition, the microporosity of these materials may lower the efficiency of wastewater treatment [20]. So, advanced adsorbents with mesopores or even hierarchical porosity are highly desired. Since the seminal work of microporous PAF-1, advance has been witnessed to construct mesoporous PAFs using pre-modified monomers through increasing the numbers of benzene rings in edge of the diamondoid topology for ammonia capture [31], hydrogen uptake [36], carbon capture [37], and heterogeneous catalysis [38]. However, no work regarding the preparation of charged PAFs with mesopores for dye removal has yet been reported.

To address the demand of charged PAF as excellent adsorbents for water treatment, this work aimed to prepare hierarchical PAF with cationic groups for selective removal of anionic dyes from water. The synthesis procedure of the target PAF is presented in Scheme 1. A new building block, pinacol 2,5-di(dimethylaminomethy)1,4-diboronate (Di-Wulff boronate), was synthesized and $\mathrm{CH}_{2} \mathrm{~N}\left(\mathrm{CH}_{3}\right)_{2}$-tagged PAF, PAF- $\mathrm{CH}_{2} \mathrm{~N}\left(\mathrm{CH}_{3}\right)_{2}$, was obtained through Suzuki polymerization with tetrakis(4-bromophenyl)methane (TBPM). After treated PAF- $\mathrm{CH}_{2} \mathrm{~N}\left(\mathrm{CH}_{3}\right)_{2}$ with methyl iodide, PAF- $\mathrm{CH}_{2} \mathrm{~N}\left(\mathrm{CH}_{3}\right)_{3}$ I was delivered. The synthesized PAFs were characterized in detail. Three organic dyes with different charge type and molecular size, methyl orange (MO), methylene blue (b-MB) and methyl blue (a-MB), were chosen to evaluated the adsorption performance of PAF- $\mathrm{CH}_{2} \mathrm{~N}\left(\mathrm{CH}_{3}\right)_{3}$ I. In addition, the regeneration and reusability study was carried out to determine its practical applicability.

\section{Experimental}

\subsection{Materials}

Tetrakis(4-bromophenyl)methane (TBPM, 98\%) was purchased form Zhengzhou Alfa Chemical (Zhengzhou, China).[1,1'-Bis(diphenylphosphino)ferrocene]dichloropalladium(II) (Pd(dppf) $\left.\mathrm{Cl}_{2}\right)(99 \%)$ and bis(pinacolato)diborane (98\%) was obtained from $\mathrm{J} \& \mathrm{~K}$ Scientific (Beijing, China). Tetrakis(triphenylphosphine) palladium (0) $\left[\mathrm{Pd}\left(\mathrm{PPh}_{3}\right)_{4}, 99 \%\right]$, anhydrous potassium acetate (99\%), N-bromosuccinimide (NBS, 99\%), 1,4-dibromo2,5-dimethylbenzene (98.5\%), p-phenylenediboronic acid (PDA, 99.5\%) and dimethylamine (33\% aqueous solution) were bought from Aladdin Chemistry (Shanghai, China). Methyl orange (MO), methylene blue (b-MB) and methyl 


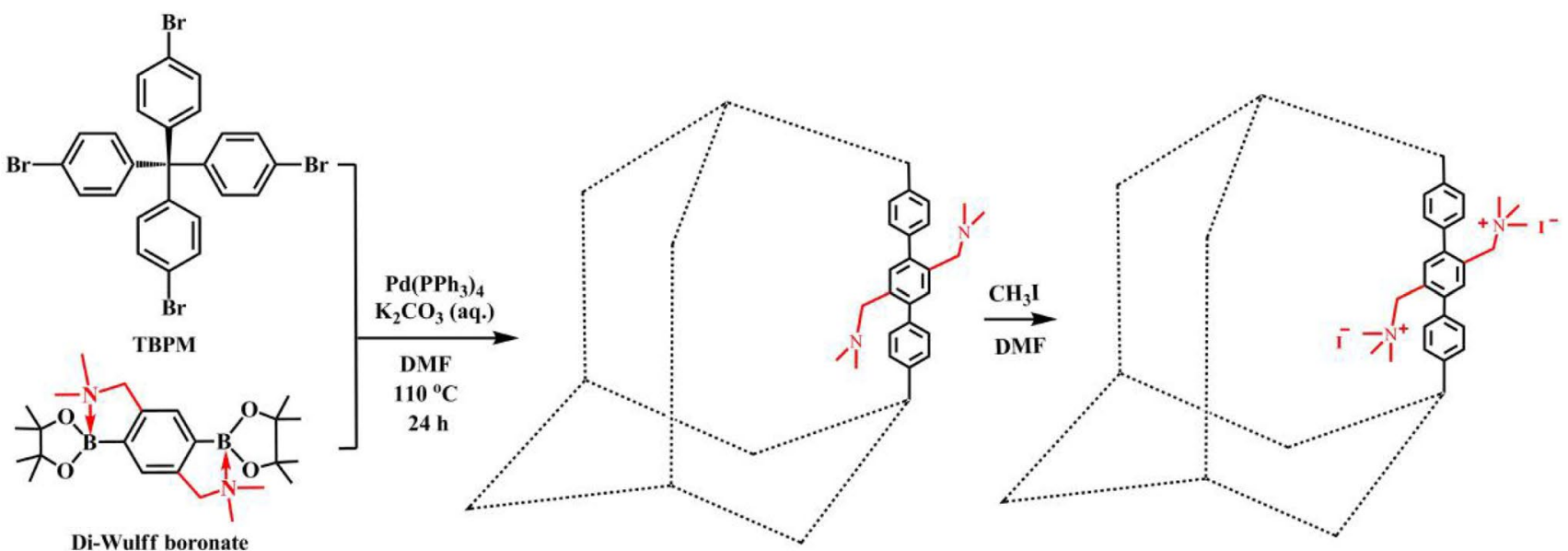

Scheme 1 Synthetic procedure for the designed cationic PAF, PAF- $\mathrm{CH}_{2} \mathrm{~N}\left(\mathrm{CH}_{3}\right)_{3} \mathrm{I}$

blue (a-MB) were from Alfa Aesar (Shanghai, China). Methanol of HPLC grade was bought from Dikma (Beijing, China). Water used in all of the chromatographic experiments was purified by a Milli-Q Ultrapure Water Purification System (Milford, USA). All other chemical reagents were of analytical grade.

\subsection{Instrumental characterization}

Fourier transform infrared spectroscopy (FT-IR) analysis was performed on a Thermo Nicolet iS10 FT-IR spectrometer in the wave-number range of $650-4000 \mathrm{~cm}^{-1}$ under ambient conditions with an attenuated total reflection (ATR) accessory. Elemental analysis were performed on a Elementar VARIO EL cube instrument. ${ }^{1} \mathrm{H}$ NMR, ${ }^{13} \mathrm{C}$ NMR and ${ }^{11} \mathrm{~B}$ NMR spectra were recorded on a Bruker Avance III HD $500 \mathrm{MHz}$ instrument. Solid-state NMR spectra were recorded on a JEOL JNM-ECZ600R instrument. The surface area and pore size distribution analysis were performed on ASAP-2460 instrument, using nitrogen adsorption and desorption at $77 \mathrm{~K}$. Samples were degassed at $80^{\circ} \mathrm{C}$ under high vacuum for $24 \mathrm{~h}$ prior to the nitrogen adsorption and desorption analysis. Scanning electron microscopy (SEM) investigations were carried out on a FEI Quanta 250/Quanta 430 instrument. Transmission electron microscopic (TEM) investigations were carried on a FEI Tecnai G2 20 instrument. Thermogravimetric analysis (TGA) was performed on a TA Q500 thermogravimeter by measuring the weight loss while heating at a rate of $10^{\circ} \mathrm{C} \mathrm{min}^{-1}$ from room temperature to $800^{\circ} \mathrm{C}$ under nitrogen. The samples were analysized on an Agilent 1200 series HPLC system. Analysis were performed at room temperature, at a flow rate of $1.0 \mathrm{~mL} \mathrm{~min}{ }^{-1}$. An Agilent XDB C18 column ( $250 \mathrm{~mm} \times 4.6 \mathrm{~mm}, 5 \mu \mathrm{m}$ ) was used for all the chromatographic analysis, using methanol and water $(80: 20, v / v)$ as mobile phase. Mobile phases were filtered through a 0.22$\mu \mathrm{m}$ membrane prior to use.

\subsection{The synthesis of the PAF- $\mathrm{CH}_{2} \mathrm{~N}\left(\mathrm{CH}_{3}\right)_{3} \mathrm{I}$}

Tetrakis-(4-bromophenyl)methane (TBPM) $(0.66 \mathrm{~g}$, $1.04 \mathrm{mmol}$ ) and Di-Wulff boronate $(0.93 \mathrm{~g}, 2.09 \mathrm{mmol})$ (the detailed synthesis and characterization of the DiWulff boronate was described in Electronic Supplementary Material, Online Resource, Figs. S1-S7) was dissolved in DMF $(90 \mathrm{~mL})$ in a round bottom flask with stirring under nitrogen, and a $2 \mathrm{M}$ aqueous solution of $\mathrm{K}_{2} \mathrm{CO}_{3}(8 \mathrm{~mL})$ and $\mathrm{Pd}\left(\mathrm{PPh}_{3}\right)_{4}(99 \mathrm{mg}, 0.08 \mathrm{mmol}$ ) were added. The flask was vacuumed and refilled with nitrogen three times and was heated to $110^{\circ} \mathrm{C}$ for $24 \mathrm{~h}$ with stirring. After cooling to room temperature, the mixture was filtrated and the crude product was washed successively with DMF, water, methanol, dichloromethane and acetone. The obtained product was dried under vacuum at $60^{\circ} \mathrm{C}$ for $24 \mathrm{~h}$. Yield: $0.69 \mathrm{~g}$ (95\%). Anal. Calcd. for $\left(\mathrm{C}_{25} \mathrm{H}_{16}\right)_{1} \cdot\left(\mathrm{C}_{12} \mathrm{H}_{18} \mathrm{~N}_{2}\right)_{2}: \mathrm{C}, 84.48 ; \mathrm{H}$, 7.47; N, 8.05. Found: $\mathrm{C}, 84.37 ; \mathrm{H}, 7.46 ; \mathrm{N}, 7.99$.

PAF- $\mathrm{CH}_{2} \mathrm{~N}\left(\mathrm{CH}_{3}\right)_{2}(0.40 \mathrm{~g})$ and DMSO $(25 \mathrm{~mL})$ were added into a round bottom flask, followed by the addition of methyl iodide $(1.3 \mathrm{~mL})$ under nitrogen. The suspension was stirred at $25^{\circ} \mathrm{C}$ for $24 \mathrm{~h}$. After reaction, the product was obtained through filtration and washed thoroughly with methanol, dichloromethane and acetone. The obtained product was dried under vacuum at $55^{\circ} \mathrm{C}$ for $24 \mathrm{~h}$. Yield: $0.72 \mathrm{~g}$ (99\%). Anal. Calcd. for $\left(\mathrm{C}_{25} \mathrm{H}_{16}\right)_{1} \cdot\left(\mathrm{C}_{14} \mathrm{H}_{24} \mathrm{~N}_{2} \mathrm{I}_{2}\right)_{2}: \mathrm{C}$, $50.32 ; \mathrm{H}, 5.06 ; \mathrm{N}, 4.43$. Found: $\mathrm{C}, 49.54 ; \mathrm{H}, 5.79 ; \mathrm{N}, 3.93$.

\subsection{Adsorption kinetic studies}

Adsorption kinetic studies were performed in $25 \mathrm{~mL}$ vials equipped with magnetic stir bars. All studies were 
conducted at ambient temperature. In a typical experiment, PAF- $\mathrm{CH}_{2} \mathrm{~N}\left(\mathrm{CH}_{3}\right)_{3} \mathrm{I}(10 \mathrm{mg})$ was added into a $10 \mathrm{~mL}$ aqueous solution of a given dye of a given concentration with magnetic stirring. Samples were taken at appropriate time interval and the suspension was filtered. The concentration of dye in the filtrate was determined with HPLC. In the study of the effect of $\mathrm{pH}$ on the adsorption efficiency, PAF- $\mathrm{CH}_{2} \mathrm{~N}\left(\mathrm{CH}_{3}\right)_{3} \mathrm{l}(10 \mathrm{mg})$ was added into a $10 \mathrm{~mL}$ aqueous solution of $\mathrm{MO}\left(50 \mathrm{mg} \mathrm{L}^{-1}\right)$ with different $\mathrm{pH}$ values and the suspension was magneticly stirred for $30 \mathrm{~min}$. Then, samples were taken and filtered. The concentration of dye in the filtrate was determined with HPLC. The concentration of dyes were determined by HPLC according to calibration curves. The dye removal efficiencies were calculated with the following equation:

Dye removal efficiency $(\%)=\frac{\left(C_{o}-C_{t}\right)}{C_{0}} \times 100 \%$

where $C_{o}\left(\mathrm{mg} \mathrm{L}^{-1}\right)$ and $C_{t}\left(\mathrm{mg} \mathrm{L}^{-1}\right)$ are the concentrations of dye before and after adsorption respectively. The amount of adsorbed dye was determined by the following equation:

$q_{t}=\frac{\left(C_{o}-C_{t}\right) V}{m}$

where $q_{t}\left(\mathrm{mg} \mathrm{g}^{-1}\right)$ is the amount of dye adsorbed per gram of adsorbent at time $t(\mathrm{~min}) ; V(\mathrm{~L})$ is the volume of the solution; $m(\mathrm{~g})$ is the mass of the adsorbent.

The adsorption kinetic behavior was explored using pseudo-second-order model, as shown by the following equation:

$\frac{t}{q_{t}}=\frac{t}{q_{e}}+\frac{t}{k_{2} q_{e}^{2}}$

where $q_{t}$ and $q_{e}\left(\mathrm{mg} \mathrm{g}^{-1}\right)$ are the adsorption capacity at certain time and equilibrium time, respectively, and $k_{2}$ $\left(\mathrm{g} \mathrm{mg}^{-1} \mathrm{~min}^{-1}\right.$ ) is the pseudo-second-order model rate constant.

\subsection{Adsorption isotherms studies}

In a typical experiment, PAF- $\mathrm{CH}_{2} \mathrm{~N}\left(\mathrm{CH}_{3}\right)_{3} \mathrm{l}(10 \mathrm{mg})$ was added into a $10 \mathrm{~mL}$ aqueous solution of a given dye with different initial concentrations (from 100 to $1000 \mathrm{mg} \mathrm{L}^{-1}$ ). The suspension was stirred overnight to reach adsorption equilibrium. The suspension was filtered and the concentration of dye in the filtrate was determined with HPLC. Furthermore, the equilibrium isotherm data are described by Langmuir isotherm model, as shown by the following equation:

SN Applied Sciences
$\frac{C_{e}}{q_{e}}=\frac{C_{e}}{q_{\max , e}}+\frac{1}{K q_{\max , e}}$

where $C_{e}\left(\mathrm{mg} \mathrm{L}^{-1}\right)$ is the equilibrium concentration of the given dye, $q_{\mathrm{e}}\left(\mathrm{mg} \mathrm{g}^{-1}\right)$ is the amount of the dye adsorbed at equilibrium, $q_{\text {max, }}$ and $K\left(\mathrm{~L} \mathrm{~mol}^{-1}\right)$ are the maximum adsorption capacity and binding energy related to Langmuir model, respectively.

\section{Results and discussion}

\subsection{Synthesis of the Di-Wulff boronate and model reaction}

The Di-Wulff boronate was synthesized from inexpensive raw material according to a previous reported method with overall yield of $60.9 \%$ [39]. The ${ }^{11} \mathrm{~B}$ NMR chemical shift of the Di-Wulff boronate is 14.60 (Online Resource, Fig. S8), indicating the presence of intramolecular B-N interaction [40]. To demonstrate the feasibility of Di-Wulff boronate as Suzuki reaction block for the synthesis of the designed PAF, a model reaction between bromobenzene and the Di-Wulff boronate was conducted and the product with target molecular structure was obtained according to the NMR characterization (Online Resource, Fig. S9 and Fig. S10).

\subsection{Characterization of the synthesized PAFs}

To confirm the success of the crosslinking of TBPM and Di-Wulff boronate, FT-IR analysis was performed. As shown in Fig. 1, in the FT-IR spectrum of TBMP, the peaks at $1479 \mathrm{~cm}^{-1}, 1006 \mathrm{~cm}^{-1}$ and $817 \mathrm{~cm}^{-1}$ can be attributed

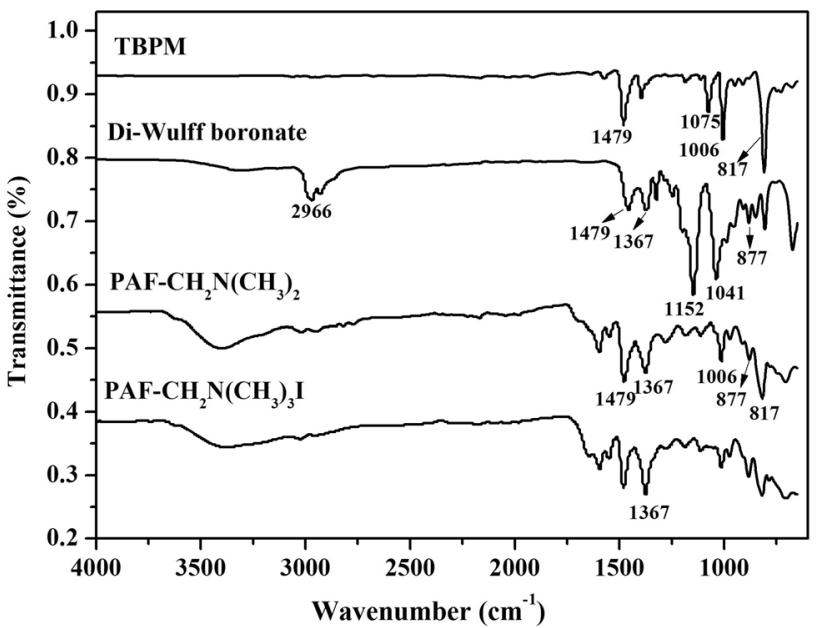

Fig. 1 FT-IR spectra of TBPM, Di-Wulff boronate, PAF- $\mathrm{CH}_{2} \mathrm{~N}\left(\mathrm{CH}_{3}\right)_{2}$ and PAF- $\mathrm{CH}_{2} \mathrm{~N}\left(\mathrm{CH}_{3}\right)_{3} \mathrm{I}$ 
to the skeleton vibration, in-plane and out-of-plane bending vibration of $\mathrm{C}-\mathrm{H}$ on the para-disubstituted benzene moieties while the spectrum of Di-Wulff boronate shows the peaks at $1367 \mathrm{~cm}^{-1}$ and $877 \mathrm{~cm}^{-1}$, attributing to the $\mathrm{C}-\mathrm{H}$ bending vibration of $\mathrm{N}\left(\mathrm{CH}_{3}\right)_{2}$ and out-of-plane bending vibration of $\mathrm{C}-\mathrm{H}$ bond on tetra-substituted benzene. These peaks are retained in the FT-IR spectrum of PAF- $\mathrm{CH}_{2} \mathrm{~N}\left(\mathrm{CH}_{3}\right)_{2}$. Meanwhile, the $\mathrm{C}-\mathrm{Br}$ stretch peak at $1075 \mathrm{~cm}^{-1}$ in the spectrum of TBMP and the peaks at $2966 \mathrm{~cm}^{-1}, 1152 \mathrm{~cm}^{-1}$ and $1041 \mathrm{~cm}^{-1}$ in the spectrum of Di-Wulff boronate, which are attributed to the $\mathrm{C}-\mathrm{H}, \mathrm{B}-\mathrm{O}$ and $\mathrm{B}-\mathrm{C}$ stretch vibration of the pinacol boronate moiety, are absent in the spectrum of PAF- $\mathrm{CH}_{2} \mathrm{~N}\left(\mathrm{CH}_{3}\right)_{2}$, indicating the successful coupling of phenyl-phenyl rings. Compared with PAF- $\mathrm{CH}_{2} \mathrm{~N}\left(\mathrm{CH}_{3}\right)_{2}$, in the FT-IR spectrum of PAF$\mathrm{CH}_{2} \mathrm{~N}\left(\mathrm{CH}_{3}\right)_{3} \mathrm{l}$, the intensity of the peak at $1367 \mathrm{~cm}^{-1}$ which correspond to $\mathrm{C}-\mathrm{H}$ bending vibration of methyl linked to nitrogen atoms shows clear increase, indicating the successful iodomethanation of the $\mathrm{N}\left(\mathrm{CH}_{3}\right)_{2}$ moieties.

To further elucidate the molecular structures of the synthesized PAFs, solid-state ${ }^{13} \mathrm{C}-\mathrm{NMR}$ (Fig. 2) and elemental analysis were conducted. As shown in Fig. 2a, the PAF$\mathrm{CH}_{2} \mathrm{~N}\left(\mathrm{CH}_{3}\right)_{2}$ retains the feature peaks of the two monomers. The peaks corresponding to pinacol boronate moiety at $78 \mathrm{ppm}$ and $25 \mathrm{ppm}$ in the spectrum of Di-Wulff boronate is not found in the spectrum of PAF- $\mathrm{CH}_{2} \mathrm{~N}\left(\mathrm{CH}_{3}\right)_{2}$ and the peak corresponding to the carbon atom linked to bromine at $121 \mathrm{ppm}$ in the spectrum of TBMP shifts to $140 \mathrm{ppm}$ in the spectrum of PAF- $\mathrm{CH}_{2} \mathrm{~N}\left(\mathrm{CH}_{3}\right)_{2}$. These results indicate the complete removal of pinacol boronate moieties and bromine atoms during the coupling of phenyl-phenyl rings. As shown in Fig. 2b, the spectrum of the nonfunctional control PAF, P2, is consistent with the published date [24]. Compared with $\mathrm{P} 2$, the spectrum of PAF- $\mathrm{CH}_{2} \mathrm{~N}\left(\mathrm{CH}_{3}\right)_{2}$ clearly demonstrates additional peaks according to the $\mathrm{CH}_{2} \mathrm{~N}\left(\mathrm{CH}_{3}\right)_{2}$ groups at 61 and $46 \mathrm{ppm}$. Compared with PAF- $\mathrm{CH}_{2} \mathrm{~N}\left(\mathrm{CH}_{3}\right)_{2}$, the peaks according to $\mathrm{CH}_{2} \mathrm{~N}\left(\mathrm{CH}_{3}\right)_{3}$ groups appear at 65 and $55 \mathrm{ppm}$ in the spectrum of PAF- $\mathrm{CH}_{2} \mathrm{~N}\left(\mathrm{CH}_{3}\right)_{3}$ land this chemical shift movement is due to the electron-withdrawing effect of the formed quaternary ammonium groups. In addition, the intensity of the peak at $55 \mathrm{ppm}$ increases obviously and this is due to the increase of methyl groups during the reaction between methyl iodide and the $\mathrm{CH}_{2} \mathrm{~N}\left(\mathrm{CH}_{3}\right)_{2}$ groups. The above results confirm the successful synthesis of the target PAF. Elemental analysis of PAF- $\mathrm{CH}_{2} \mathrm{~N}\left(\mathrm{CH}_{3}\right)_{3}$ I reveals a nitrogen content of $3.93 \mathrm{wt} \%$, corresponding to $2.81 \mathrm{mmol} \mathrm{g}^{-1}$ or $52.27 \mathrm{wt} \%$ of the charged $\mathrm{N}\left(\mathrm{CH}_{3}\right)_{3}$ l groups.

The porosity of the PAF- $\mathrm{CH}_{2} \mathrm{~N}\left(\mathrm{CH}_{3}\right)_{3}$ I was characterized by nitrogen adsorption-desorption isotherm measurement at $77 \mathrm{~K}$. As shown in Fig. 3a, PAF- $\mathrm{CH}_{2} \mathrm{~N}\left(\mathrm{CH}_{3}\right)_{3}$ I shows a type I isotherm. A rapid uptake of nitrogen at low relative pressure indicates the existence of micropores while a hysteresis in the desorption branch reflects the existence of mesopores. The Brunauer-Emmet-Teller (BET) surface area of PAF- $\mathrm{CH}_{2} \mathrm{~N}\left(\mathrm{CH}_{3}\right)_{3} \mathrm{l}$ is $524.74 \mathrm{~m}^{2} \mathrm{~g}^{-1}$. As shown in Fig. 3b, the pore size distribution of PAF- $\mathrm{CH}_{2} \mathrm{~N}\left(\mathrm{CH}_{3}\right)_{3}$ I reveals the presence of micropores and the coexistence of mesopores in the range of 2.0 to $4.6 \mathrm{~nm}$. Compared with that of PAF$\mathrm{CH}_{2} \mathrm{~N}\left(\mathrm{CH}_{3}\right)_{2}$, PAF- $\mathrm{CH}_{2} \mathrm{~N}\left(\mathrm{CH}_{3}\right)_{3}$ l showed a decrease of BET surface area and a reduction of pore size (Online Resource, Fig. S11). These results consisted with the treatment of PAF- $\mathrm{CH}_{2} \mathrm{~N}\left(\mathrm{CH}_{3}\right)_{2}$ with methyl iodide. Scanning electron microscopy (SEM) images show that the PAF- $\mathrm{CH}_{2} \mathrm{~N}\left(\mathrm{CH}_{3}\right)_{3} \mathrm{I}$ is composed of aggregated particles with micron sizes (Online Resource, Fig. S12a and S12b) while the transmission electron microscopy (TEM) images reveal the same morphology and the presence of pores (Online Resource, Fig. $\mathrm{S} 12 \mathrm{c}$ and $\mathrm{S} 12 \mathrm{~d}$ ). The hierarchical porosity and the micron sizes of PAF- $\mathrm{CH}_{2} \mathrm{~N}\left(\mathrm{CH}_{3}\right)_{3}$ I make it ideal candidate as
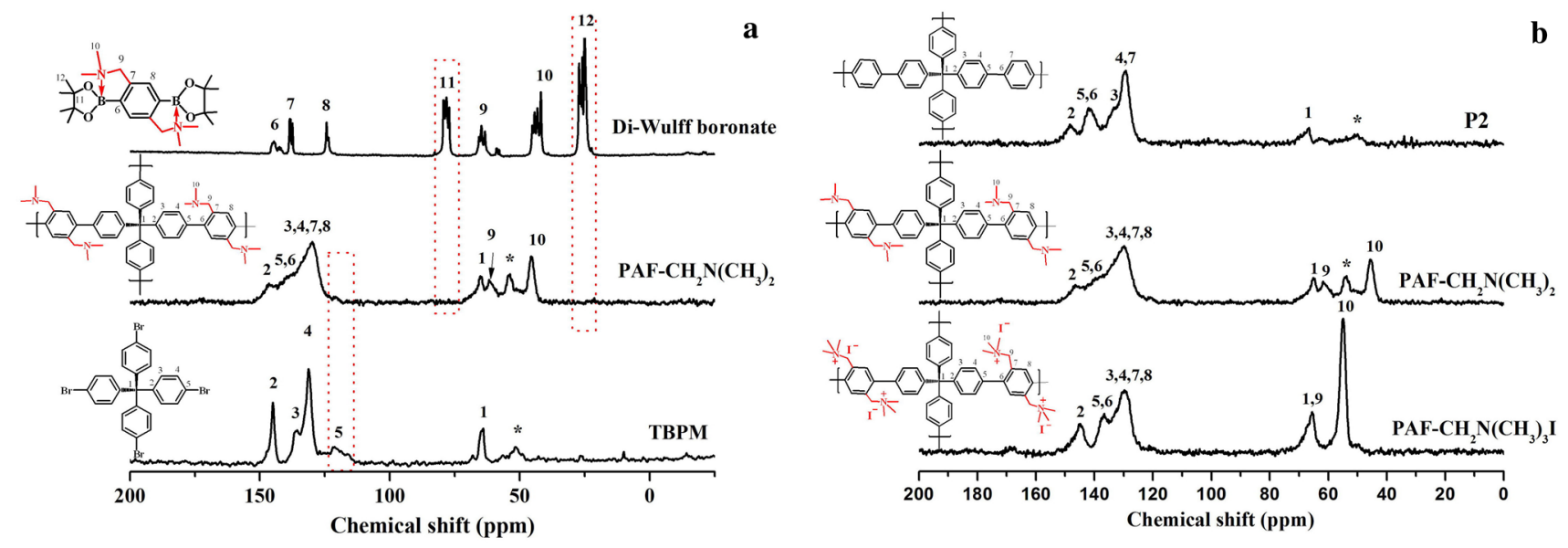

Fig. 2 a Solid-state ${ }^{13} \mathrm{C}$ NMR spectra of Di-Wulff boronate, PAF- $\mathrm{CH}_{2} \mathrm{~N}\left(\mathrm{CH}_{3}\right)_{2}$ and TBPM, b Solid-state ${ }^{13} \mathrm{C} \mathrm{NMR} \mathrm{spectra} \mathrm{of} \mathrm{P2,} \mathrm{PAF-CH}_{2} \mathrm{~N}\left(\mathrm{CH}_{3}\right)_{2}$ and PAF- $\mathrm{CH}_{2} \mathrm{~N}\left(\mathrm{CH}_{3}\right)_{3} \mathrm{I}$ 

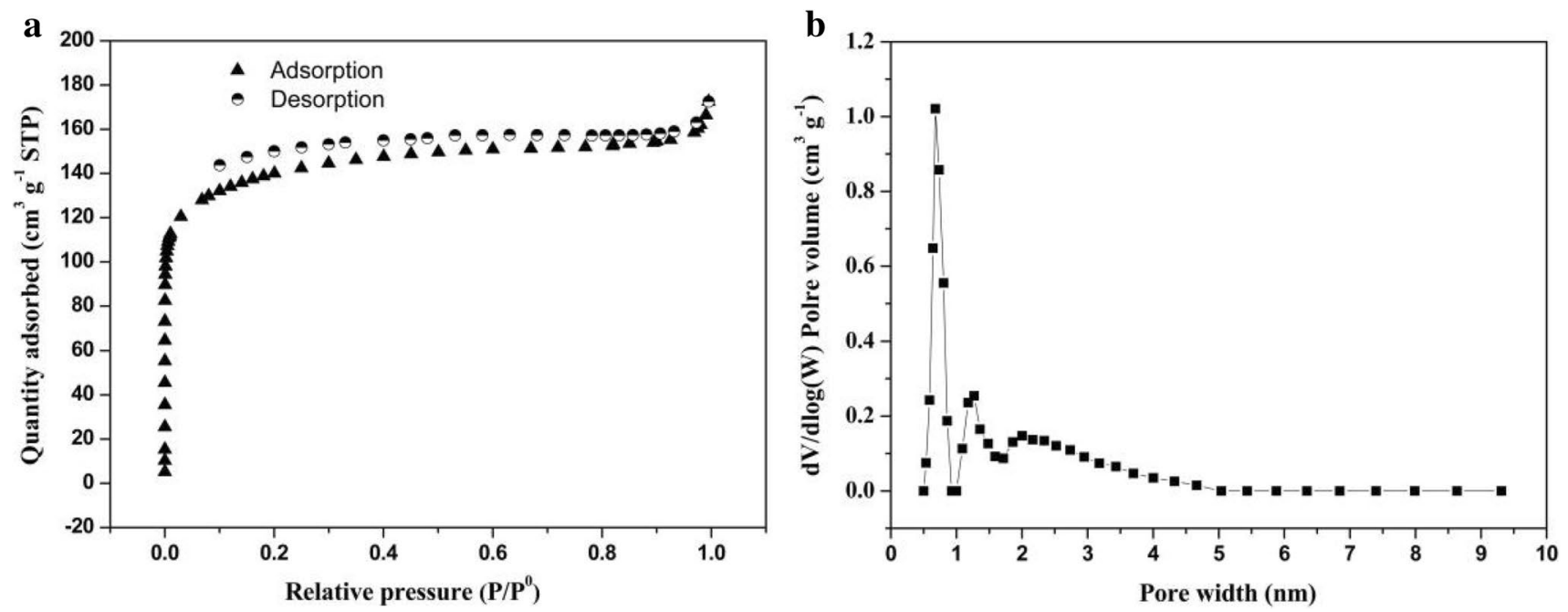

Fig. 3 a $\mathrm{N}_{2}$ adsorption isotherm of PAF- $\mathrm{CH}_{2} \mathrm{~N}\left(\mathrm{CH}_{3}\right)_{3}$ I measured at $77 \mathrm{~K}$, b Pore size distribution of PAF- $\mathrm{CH}_{2} \mathrm{~N}\left(\mathrm{CH}_{3}\right)_{3}$ I from the $\mathrm{N}_{2}$ adsorption isotherm

adsorbent. Additionally, thermogravimetric analysis (TGA) reveals the good stability of PAF- $\mathrm{CH}_{2} \mathrm{~N}\left(\mathrm{CH}_{3}\right)_{3}$ l up to 200 oC under nitrogen (Online Resource, Fig. S13).

\subsection{Adsorption kinetic studies}

The PAF- $\mathrm{CH}_{2} \mathrm{~N}\left(\mathrm{CH}_{3}\right)_{3}$ I was used directly as adsorbent for dye removal from water. As a proof of concept, we first chose two widely applied organic dyes for the test, methyl orange (MO) as an anionic dye and methylene blue (b-MB) as an cationic dye. These two dyes were with the similar dimensions $(18.17 \AA \times 7.61 \AA \times 5.74 \AA$ for $\mathrm{MO}$ and $17.29 \AA \times 8.19 \AA \times 4.11 \AA$ for $b-M B$, Online Resource, Fig. S15) [14]. The adsorption experiments were performed by mixing $10 \mathrm{mg}$ of PAF- $\mathrm{CH}_{2} \mathrm{~N}\left(\mathrm{CH}_{3}\right)_{3} \mathrm{l}$ and the tested dyes with the same concentrations $\left(50 \mathrm{mg} \mathrm{L}^{-1}, 10 \mathrm{~mL}\right.$ ), and HPLC spectra were recorded periodically for the filtered solution. As shown in Fig. 4, $\mathrm{MO}$ molecules are almost completely captured by PAF- $-\mathrm{CH}_{2} \mathrm{~N}\left(\mathrm{CH}_{3}\right)_{3}$ in about $0.5 \mathrm{~min}$, whereas the b-MB molecules remain in the solution. The optical images obviously reveal that the $\mathrm{MO}$ solution became clear within 0.5 min of treatment with PAF- $\mathrm{CH}_{2} \mathrm{~N}\left(\mathrm{CH}_{3}\right)_{3} \mathrm{I}$ while the $\mathrm{b}-\mathrm{MB}$ solution remained almost unchanged even after 180 min of treatment with PAF- $\mathrm{CH}_{2} \mathrm{~N}\left(\mathrm{CH}_{3}\right)_{3}$ l. This result indicates the excellent selectivity of PAF- $\mathrm{CH}_{2} \mathrm{~N}\left(\mathrm{CH}_{3}\right)_{3} \mathrm{I}$ towards anionic dye. To further investigate the properties of PAF- $\mathrm{CH}_{2} \mathrm{~N}\left(\mathrm{CH}_{3}\right)_{3}$ l, adsorption performance of PAF$\mathrm{CH}_{2} \mathrm{~N}\left(\mathrm{CH}_{3}\right)_{2}$ towards $\mathrm{MO}$ and b-MB were also carried out and compared with that of PAF- $\mathrm{CH}_{2} \mathrm{~N}\left(\mathrm{CH}_{3}\right)_{3}$ l. As shown in Fig. S16, the adsorption efficiencies of PAF- $\mathrm{CH}_{2} \mathrm{~N}\left(\mathrm{CH}_{3}\right)_{2}$ towards $\mathrm{MO}$ and $\mathrm{b}-\mathrm{MB}$ are $80 \%$ and $60 \%$ respectively. This is due to the hydrophobicity of the PAF skeleton and weak anion exchange of the $\mathrm{CH}_{2} \mathrm{~N}\left(\mathrm{CH}_{3}\right)_{2}$ motifs. After theated with methyl iodide, $\mathrm{CH}_{2} \mathrm{~N}\left(\mathrm{CH}_{3}\right)_{3} I$ motifs showed strong anion exchange ability. And the adsorption efficiencies of PAF- $\mathrm{CH}_{2} \mathrm{~N}\left(\mathrm{CH}_{3}\right)_{3}$ l towards $\mathrm{MO}$ and b-MB changed to be $100 \%$ and $8 \%$. These results further indicated the excellent selectivity of PAF- $\mathrm{CH}_{2} \mathrm{~N}\left(\mathrm{CH}_{3}\right)_{3}$ l towards anionic dye.

The adsorption rate and dye removal efficiency of PAF$\mathrm{CH}_{2} \mathrm{~N}\left(\mathrm{CH}_{3}\right)_{3}$ l was further investigated. As shown in Fig. 5a and Fig. S17, the adsorption equilibrium of $\mathrm{MO}$ is achieved in only $0.5 \mathrm{~min}$ for $50 \mathrm{mg} \mathrm{L}^{-1}$ and $100 \mathrm{mg} \mathrm{L}^{-1} \mathrm{MO}$ solution while $1.5 \mathrm{~min}$ and $5 \mathrm{~min}$ are required for 200 and $400 \mathrm{mg} \mathrm{L}^{-1}$, respectively. Figure $5 \mathrm{~b}$ shows the pseudo-second-order fitting linear curves of $\mathrm{MO}$ on PAF- $\mathrm{CH}_{2} \mathrm{~N}\left(\mathrm{CH}_{3}\right)_{3} \mathrm{I}$ and the corresponding pseudo-second-order rate constants $\left(k_{o b s}\right)$ at different MO concentrations. The correlation coefficients $R^{2}$ are all equal to 1 , indicating that the adsorption behavior between PAF- $\mathrm{CH}_{2} \mathrm{~N}\left(\mathrm{CH}_{3}\right)_{3}$ land $\mathrm{MO}$ is mainly attributed to chemical interaction. The $k_{o b s}$ value for $50 \mathrm{mg} \mathrm{L}^{-1} \mathrm{MO}$ solution is as high as $4.28 \mathrm{~g} \mathrm{mg}^{-1} \mathrm{~min}^{-1}$ and a value of $0.038 \mathrm{~g} \mathrm{mg}^{-1} \mathrm{~min}^{-1}$ is obtained even when the $\mathrm{MO}$ solution is $400 \mathrm{mg} \mathrm{L}^{-1}$, which are significantly higher than those of other reported cationic adsorbents [17]. It is known that the adsorption efficiency is strongly influenced by the dye concentrations and dosage of the adsorbents [41]. It can be seen form Fig. 5a, c, the MO adsorption efficiency is nearly $100 \%$ when $\mathrm{MO}$ concentration is not higher than $400 \mathrm{mg} \mathrm{L}^{-1}$ and it reaches $94 \%$ even for $600 \mathrm{mg} \mathrm{L}^{-1} \mathrm{MO}$ solution. Besides, the effect of $\mathrm{pH}$ on the $\mathrm{MO}$ adsorption efficiency was evaluated. As shown in Fig. $5 \mathrm{~d}$, in the $\mathrm{pH}$ range of 2 to 12 , the adsorption efficiencies are above $96.4 \%(\mathrm{pH} \mathrm{2})$, indicating the good stability and practicability of PAF- $\mathrm{CH}_{2} \mathrm{~N}\left(\mathrm{CH}_{3}\right)_{3}$ l. Although solution $\mathrm{pH}$ values had a direct influence on the charged state of anionic dye molecule and might reduce the electrostatic 

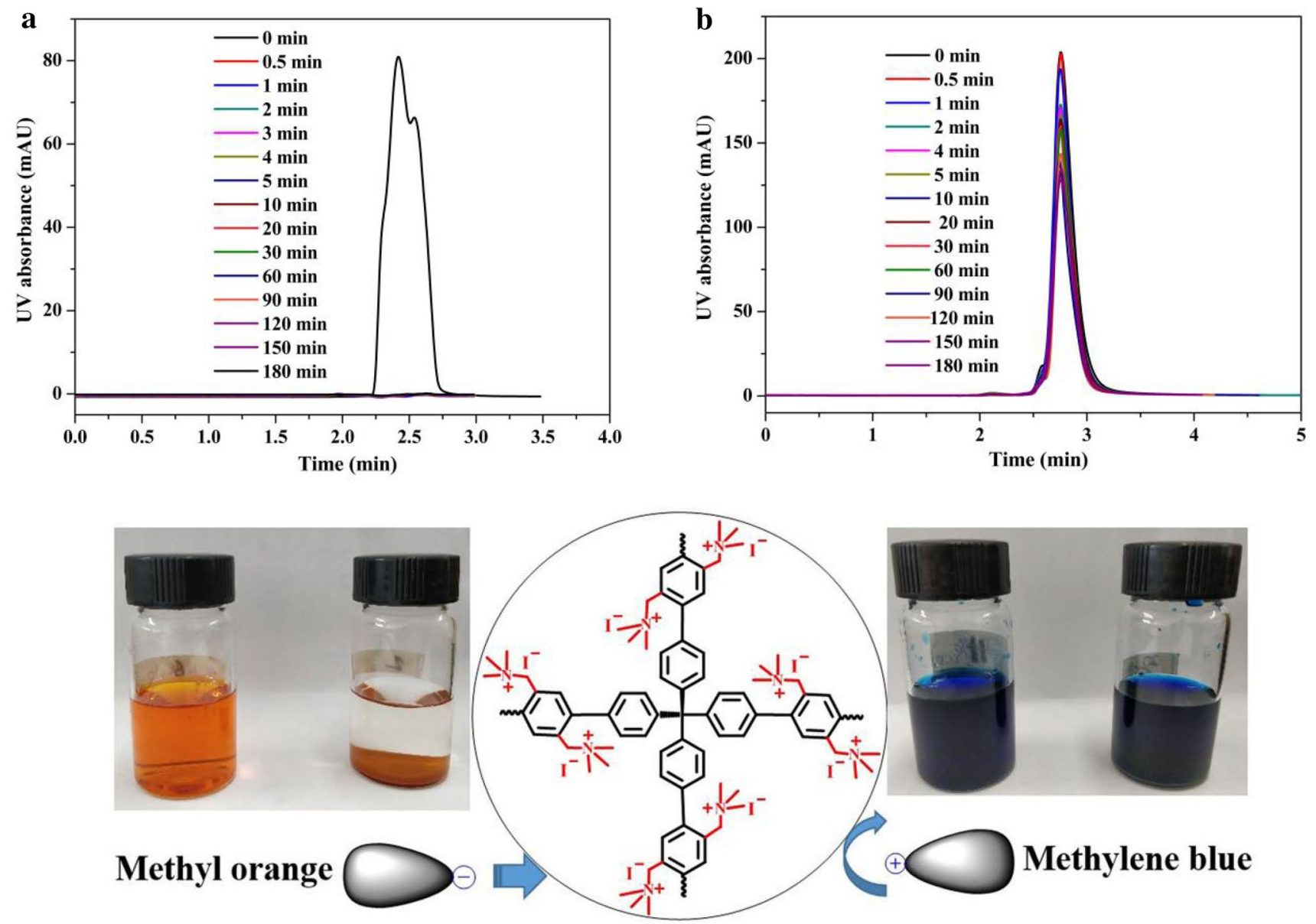

Fig. 4 The adsorption selectivity of PAF- $\mathrm{CH}_{2} \mathrm{~N}\left(\mathrm{CH}_{3}\right)_{3}$ l. Including HPLC spectra of MO (a) and b-MB (b) recorded at different contact times with PAF- $\mathrm{CH}_{2} \mathrm{~N}\left(\mathrm{CH}_{3}\right)_{3}$ l and photographs of $\mathrm{MO}$ (left) and b-MB (right) solutions before and after treatment with PAF- $\mathrm{CH}_{2} \mathrm{~N}\left(\mathrm{CH}_{3}\right)_{3} \mathrm{I}$

interaction with cationic adsorbent, the hydrophobic interaction between dye and adsorbent was not influenced. So, the $\mathrm{pH}$ values showed little influence on the adsorption efficiencies under the tested conditions. The high adsorption rate and high adsorption efficiency may be due to the hierarchical structure and the dense and homogeneous distribution of cationic moieties of PAF- $\mathrm{CH}_{2} \mathrm{~N}\left(\mathrm{CH}_{3}\right)_{3} \mathrm{l}$. The presence of mesopores can serve as a diffusion pathway, allowing for the rapid diffusion of the dye molecules into the interior of the adsorbent. The high density and distribution homogeneity of the cationic moieties endows the charged PAF with generous and accessible binding sites for dye molecular. The $\mathrm{N}_{2}$ adsorption isotherm and pore size distribution of PAF- $\mathrm{CH}_{2} \mathrm{~N}\left(\mathrm{CH}_{3}\right)_{3}$ I after MO adsorption was tested to further reveal the adsorption performance of the synthesized adsorbent. As showed in Fig. S18, the BET surface area of PAF- $\mathrm{CH}_{2} \mathrm{~N}\left(\mathrm{CH}_{3}\right)_{3}$ I decreased to $25.24 \mathrm{~m}^{2} \mathrm{~g}^{-1}$ after $\mathrm{MO}$ adsorption. This result indicated that the pore of PAF- $\mathrm{CH}_{2} \mathrm{~N}\left(\mathrm{CH}_{3}\right)$ was occupied by MO molecule.

To further reveal the effect of mesopores to the adsorption properties of PAF- $\mathrm{CH}_{2} \mathrm{~N}\left(\mathrm{CH}_{3}\right)_{3} \mathrm{l}$, a large-sized dye, methyl blue (a-MB) with a dimension of $24.50 \AA \times 14.40 \AA \times 13.90 \AA$, which could not be absorbed by cationic adsorbents with microporous structure [14, 21], was chose for further test. As shown in Fig. 6a and Fig. S19, the a-MB molecular can be completely adsorbed by PAF- $\mathrm{CH}_{2} \mathrm{~N}\left(\mathrm{CH}_{3}\right)_{3}$ in only $1 \mathrm{~min}$ and $8 \mathrm{~min}$ for $50 \mathrm{mg}$ $\mathrm{L}^{-1}$ and $100 \mathrm{mg} \mathrm{L}^{-1} \mathrm{a}-\mathrm{MB}$ solutions, respectively. Even when the a-MB concentration is $200 \mathrm{mg} \mathrm{L}^{-1}$, the complete capture of a-MB still can be achieved in just $1 \mathrm{~h}$. It can be seen form Fig. $6 \mathrm{~b}$ that the $k_{\text {obs }}$ value for $50 \mathrm{mg} \mathrm{L}^{-1}$ a-MB solution is as high as $1.38 \mathrm{~g} \mathrm{mg}^{-1} \mathrm{~min}^{-1}$ and a value of $0.0018 \mathrm{~g} \mathrm{mg}^{-1} \mathrm{~min}^{-1}$ is obtained even when the a-MB solution is $200 \mathrm{mg} \mathrm{L}^{-1}$. Those $k_{\text {obs }}$ values are great higher than the reported cationic porous polymer [17]. Compared with PAF-1-based cationic adsorbent, which was microporous and excluded a-MB [21], this quick adsorption rate and high adsorption efficiency is a another sound proof of the merit of the presence of mesopores in PAF- $-\mathrm{CH}_{2} \mathrm{~N}\left(\mathrm{CH}_{3}\right)_{3}$ l. 

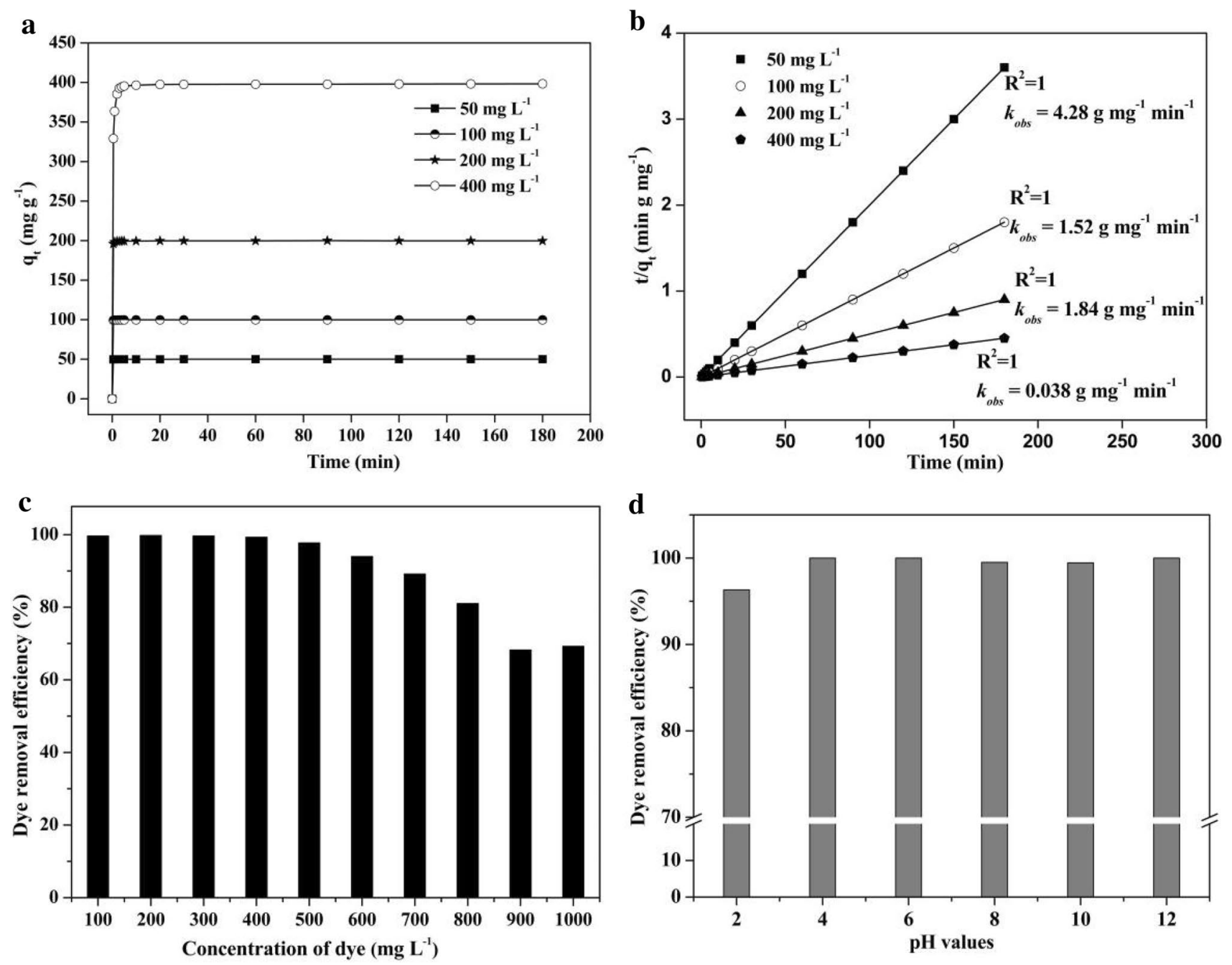

Fig. 5 a The time-dependent adsorption of $\mathrm{MO}$ with different concentrations by PAF- $-\mathrm{CH}_{2} \mathrm{~N}\left(\mathrm{CH}_{3}\right)_{3}$ l, b The linear fitting plots of $\mathrm{MO}$ adsorption kinetic onto PAF- $\mathrm{CH}_{2} \mathrm{~N}\left(\mathrm{CH}_{3}\right)_{3}$ I of pseudo-second-order kinetic model, c Adsorption efficiency of $\mathrm{MO}$ by PAF- $\mathrm{CH}_{2} \mathrm{~N}\left(\mathrm{CH}_{3}\right)_{3} \mathrm{I}$

\subsection{Adsorption isotherms studies}

The adsorption capacity of PAF- $\mathrm{CH}_{2} \mathrm{~N}\left(\mathrm{CH}_{3}\right)_{3}$ I was investigated by Langmuir adsorption isotherm measurement (Fig. 7a). And through the corresponding linear fitting (Fig. 7b), the related equilibrium parameters can be determined. The maximum adsorption capacity, $q_{\text {max,e, }}$ for $\mathrm{MO}$ and a-MB are as high as $690 \mathrm{mg} \mathrm{g}^{-1}$ and $476 \mathrm{mg} \mathrm{g}^{-1}$ respectively, whereas the value for $\mathrm{b}-\mathrm{MB}$ is only $21 \mathrm{mg} \mathrm{g}^{-1}$, further indicating the excellent selectivity of PAF- $\mathrm{CH}_{2} \mathrm{~N}\left(\mathrm{CH}_{3}\right)_{3}$ l. The $q_{\text {max,e }}$ of for $\mathrm{MO}$ is great higher than the reported adsorbents $[13,42,43]$. The $q_{\text {max,e }}$ value of $690 \mathrm{mg} \mathrm{g}^{-1}$ for MO corresponds to $2.11 \mathrm{mmol} \mathrm{g}^{-1}$, which is a little lower than the calculated charged $\mathrm{N}\left(\mathrm{CH}_{3}\right)_{3}$ l groups of $2.81 \mathrm{mmol} \mathrm{g}^{-1}$, demonstrating that even through the charged PAF was highly crosslinked, most of the charged $\mathrm{N}\left(\mathrm{CH}_{3}\right)_{3}$ l groups in

for different concentrations of $\mathrm{MO}, \mathbf{d}$ Adsorption efficiency of $\mathrm{MO}$ by PAF- $\mathrm{CH}_{2} \mathrm{~N}\left(\mathrm{CH}_{3}\right)_{3} \mathrm{l}$ after a constant time of 30 min at different $\mathrm{pH}$ values ( $\mathrm{MO}$ concentration was $50 \mathrm{mg} \mathrm{L}^{-1}$ )

the framework could behave as freely accessible reactive groups. In addition, the formation constant, $K$, are 78,045 and $239,502 \mathrm{~L} \mathrm{~mol}^{-1}$ for $\mathrm{MO}$ and a-MB, respectively. Those values are greater than the reported values $[17,44]$, implicating the strong affinity of PAF- $\mathrm{CH}_{2} \mathrm{~N}\left(\mathrm{CH}_{3}\right)_{3}$ I towards anionic dyes.

\subsection{Regeneration and reusability}

The regeneration and reusability are essential properties of a adsorbent. In this context, the recycling of PAF- $\mathrm{CH}_{2} \mathrm{~N}\left(\mathrm{CH}_{3}\right)_{3} \mathrm{I}$ for $\mathrm{MO}$ adsorption was investigated. The adsorbed $\mathrm{MO}$ could be readily desorbed from PAF$\mathrm{CH}_{2} \mathrm{~N}\left(\mathrm{CH}_{3}\right)_{3} \mathrm{l}$ by immersion in $1 \mathrm{M} \mathrm{Nal}$ ethanolic solution (water: ethanol, 1:1, v/v) for 30 min with stirring. As shown in Fig. S20, the optical image of the regenerated 

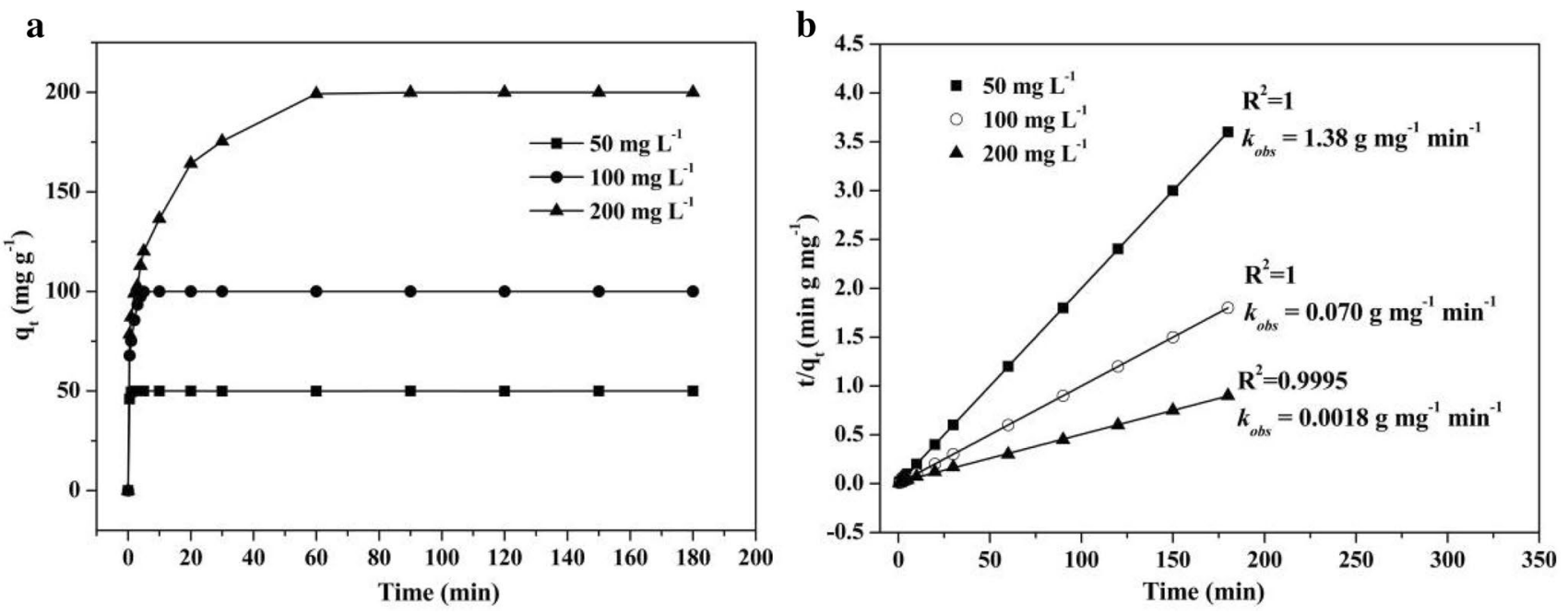

Fig. 6 a The time-dependent adsorption of a-MB with different concentrations by PAF- $\mathrm{CH}_{2} \mathrm{~N}\left(\mathrm{CH}_{3}\right)_{3} \mathrm{l}$, b The linear fitting plots of MO adsorption kinetic onto PAF- $\mathrm{CH}_{2} \mathrm{~N}\left(\mathrm{CH}_{3}\right)_{3}$ l of pseudo-second-order kinetic model
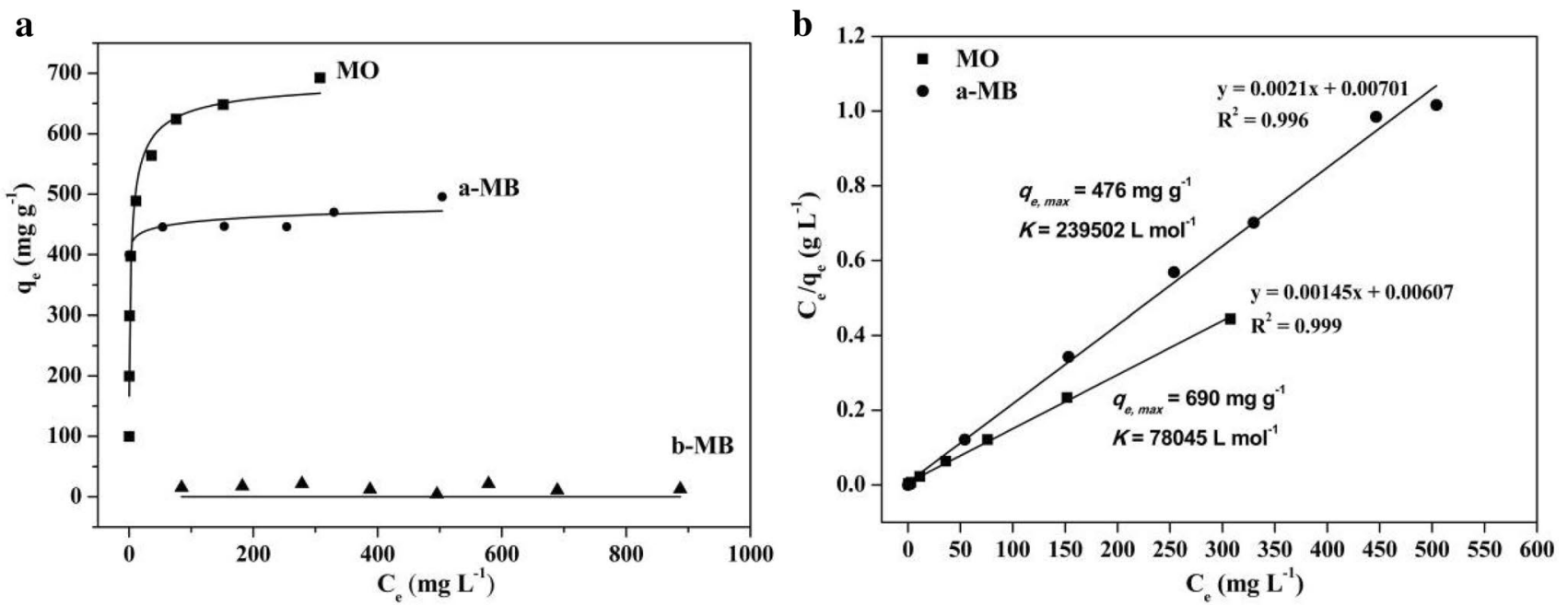

Fig. 7 a Fitting curves of $\mathrm{MO}$, a-MB and b-MB onto PAF- $\mathrm{CH}_{2} \mathrm{~N}\left(\mathrm{CH}_{3}\right)_{3}$ l of Langmuir isotherm model, $\mathbf{b}$ linear fitting plots of $\mathrm{MO}$ and a-MB onto PAF- $\mathrm{CH}_{2} \mathrm{~N}\left(\mathrm{CH}_{3}\right)_{3}$ l of Langmuir isotherm model

adsorbent clearly show that the adsorbed MO is effectively desorbed. The FT-IR spectra presented in Fig. S21 further proves the efficient removal of adsorbed MO molecules. The regenerated adsorbent was washed with water three times and reused in a next $\mathrm{MO}$ adsorption cycle. As shown in Fig. 8, PAF- $\mathrm{CH}_{2} \mathrm{~N}\left(\mathrm{CH}_{3}\right)_{3}$ I retains about $99 \%$ of its initial adsorption efficiency after 10 adsorption-desorption cycles, even when the MO concentration was as high as $200 \mathrm{mg} \mathrm{L}^{-1}$. This result indicates that the PAF- $\mathrm{CH}_{2} \mathrm{~N}\left(\mathrm{CH}_{3}\right)_{3}$ I has good reusability and this can be attributed to its hierarchical structure, which facilitates fast diffusion of dye molecules and greatly increases the adsorption-desorption rate.

\section{Conclusions}

In summary, a charged PAF, PAF- $\mathrm{CH}_{2} \mathrm{~N}\left(\mathrm{CH}_{3}\right)_{3}$ l, which was densely and homogeneously functionalized with cationic groups and featured with hierarchical porosity, has been successfully synthesized. It shows excellent selectivity towards anionic dye. The hierarchical porosity structure and the high density and homogeneous distribution of the cationic moieties endow the PAF$\mathrm{CH}_{2} \mathrm{~N}\left(\mathrm{CH}_{3}\right)_{3}$ I with strong affinity, fast adsorption rate, high adsorption efficiency and adsorption capacities towards not only small anionic dye but also large-sized 


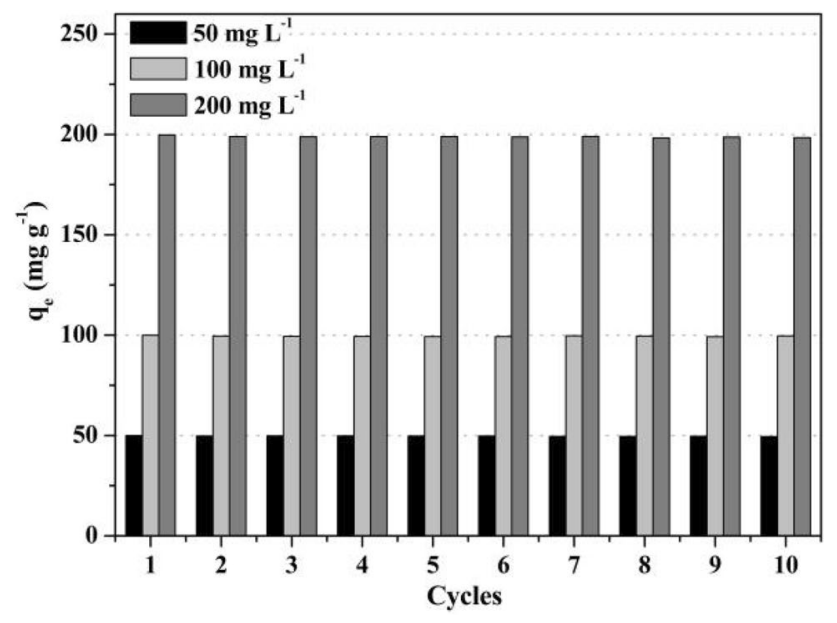

Fig. 8 The recyclability of PAF- $\mathrm{CH}_{2} \mathrm{~N}\left(\mathrm{CH}_{3}\right)_{3}$ I for the adsorption of MO

one. Additionally, the hierarchical structure of PAF$\mathrm{CH}_{2} \mathrm{~N}\left(\mathrm{CH}_{3}\right)_{3} \mathrm{l}$ is also beneficial for its regeneration. The regenerated PAF- $\mathrm{CH}_{2} \mathrm{~N}\left(\mathrm{CH}_{3}\right)_{3}$ l can retain about $99 \%$ of its initial adsorption efficiency even after 10 adsorption-desorption cycles. These excellent features show that PAF- $\mathrm{CH}_{2} \mathrm{~N}\left(\mathrm{CH}_{3}\right)_{3}$ I is a promising adsorbent for wastewater treatment. This study highlights the significance of functionalization and porosity regulation towards the application of PAFs, expanding the application scope of PAFs but also promoting the development of PAFs-based advanced materials.

Acknowledgements The authors are grateful to Jiangsu science and technology project (BK20170471, BK20191479) and the National Natural Science Foundation of China (21974120, 21876144 and 21675139). This work is also supported by the Opening foundation of Key Laboratory of Drug Quality Control and Pharmacovigilance (China Pharmaceutical University), Ministry of Education.

Author Contribution All authors contributed to the study conception and design. Material preparation, data collection and analysis were performed by Wenjie Yu, Lin Zhang and Jing Liu. The first draft of the manuscript was written by Hengye Li, Fenying Kong and Wei Wang. All authors commented on previous versions of the manuscript. All authors read and approved the final manuscript.

\section{Compliance with ethical standards}

Conflict of interest The authors declare that they have no conflict of interest.

\section{References}

1. Kyzas G, Fu J, Matis K (2013) The change from past to future for adsorbent materials in treatment of dyeing wastewaters. Materials 6:5131-5158
2. Yuan J, Liu X, Akbulut O, Hu J, Suib SL, Kong J, Stellacci F (2008) Superwetting nanowire membranes for selective absorption. Nat Nanotech 3:332-336

3. Pan B, Pan B, Zhang W, Lv L, Zhang Q, Zheng S (2009) Development of polymeric and polymer-based hybrid adsorbents for pollutants removal from waters. Chem Eng J 151:19-29

4. Lei W, Portehault D, Liu D, Qin S, Chen Y (2013) Porous boron nitride nanosheets for effective water cleaning. Nat commun 4:1777-1784

5. Alsbaiee A, Smith BJ, Xiao L, Ling Y, Helbling DE, Dichtel WR (2015) Rapid removal of organic micropollutants from water by a porous $\beta$-cyclodextrin polymer. Nature 529:190-194

6. Davis ME (2002) Ordered porous materials for emerging applications. Nature 417:813-821

7. Hameed BH, Din ATM, Ahmad AL (2007) Adsorption of methylene blue onto bamboo-based activated carbon: kinetics and equilibrium studies. J Hazard Mater 141:819-825

8. Wang S, Peng Y (2010) Natural zeolites as effective adsorbents in water and wastewater treatment. Chem Eng J 156:11-24

9. Yan Z, Tao S, Yin J, Li G (2006) Mesoporous silicas functionalized with a high density of carboxylate groups as efficient absorbents for the removal of basic dye stuffs. J Mater Chem 16:2347-2353

10. Gui C, Wang Q, Hao S, Qu J, Huang P, Cao C, Song W, Yu Z (2014) Sandwichlike magnesium silicate/reduced graphene oxide nanocomposite for enhanced $\mathrm{Pb} \backslash \mathrm{r}^{2+} \backslash \mathrm{r}$ and methylene blue adsorption. ACS Appl Mater Interfaces 6:4653-14659

11. Haque $E$, Jun JW, Jhung SH (2011) Adsorptive removal of methyl orange and methylene blue from aqueous solution with a metal-organic framework material, iron terephthalate (MOF235). J Hazard Mater 185:507-511

12. Li J, Wang C, Fu H, Cui J, Xu P, Guo J, Li J (2017) High-performance adsorption and separation of anionic dyes in water using a chemically stable graphene-like metal-organic framework. Dalton Trans 46:10197-10201

13. Liu Y, Luo C, Sun J, Li H, Sun Z, Yan S (2015) Enhanced adsorption removal of methyl orange from aqueous solution by nanostructured proton-containing $\delta-\mathrm{MnO}_{2}$. J Mater Chem A 3:5674-5682

14. Li Z, Li H, Guan X, Tang J, Yusran Y, Li Z, Xue M, Fang Q, Yan Y, Valtchev V, Qiu S (2017) Three-dimensional ionic covalent organic frameworks for rapid, reversible, and selective ion exchange. J Am Chem Soc 139:17771-17774

15. Ji W, Xiao L, Ling Y, Ching C, Matsumoto M, Bisbey RP, Helbling DE, Dichtel WR (2018) Removal of genX and perfluorinated alkyl substances from water by amine-functionalized covalent organic frameworks. J Am Chem Soc 140:12677-12681

16. Liu Y, Ma Y, Yang J, Diercks CS, Tamura N, Jin F, Yaghi OM (2018) Molecular weaving of covalent organic frameworks for adaptive guest inclusion. J Am Chem Soc 140:16015-16019

17. Shen X, Ma S, Xia H, Shi Z, Mu Y, Liu X (2018) Cationic porous organic polymers as an excellent platform for highly efficient removal of pollutants from water. J Mater Chem A 6:20653-20658

18. Xiong G, Wang B, You L, Ren B, He Y, Ding F, Dragutan I, Dragu$\tan V$, Sun $Y(2019)$ Hypervalent silicon-based, anionic porous organic polymers with solid microsphere or hollow nanotube morphologies and exceptional capacity for selective adsorption of cationic dyes. J Mater Chem A 7:393-404

19. Liu Z, Cao C, Han B (2019) A cationic porous organic polymer for high-capacity, fast, and selective capture of anionic pollutants. J Hazard Mater 367:348-355

20. Li B, Zhang Y, Ma D, Shi Z, Ma S (2014) Mercury nano-trap for effective and efficient removal of mercury(II) from aqueous solution. Nat Commun 5:5537-5543

21. Li B, Zhang Y, Ma D, Xing Z, Ma T, Shi Z, Ji X, Ma S (2016) Creation of a new type of ion exchange material for rapid, high-capacity, 
reversible and selective ion exchange without swelling and entrainment. Chem Sci 7:2138-2144

22. Lee $S$, Barin $G$, Ackerman $C M$, Muchenditsi $A, X u$ J, Reimer JA, Lutsenko S, Long JR, Chang CJ (2016) Copper capture in a thioether-functionalized porous polymer applied to the detection of Wilson's disease. J Am Chem Soc 138:7603-7609

23. Zhao D, Tian Y, Jing X, Lu Y, Zhu G (2019) PAF-1@cellulose nanofibril composite aerogel for highly-efficient removal of bisphenol A. J Mater Chem A 7:157-164

24. Kamcev J, Taylor MK, Shin DM, Jarenwattananon NN, Colwell KA, Long JR (2019) Functionalized porous aromatic frameworks as high-performance adsorbents for the rapid removal of boric acid from water. Adv Mater 31:1808027-1808035

25. Zhang L, Sun J, Sun F, Chen P, Liu J, Zhu G (2019) Facile synthesis of ultrastable porous aromatic frameworks by Suzuki-Miyaura coupling reaction for adsorption removal of organic dyes. Chem Eur J 25:3903-3908

26. Shen X, Faheem M, Matsuo Y, Aziz S, Zhang X, Li Y, Song J, Tian $Y$, Zhu G (2019) Polarity engineering of porous aromatic frameworks for specific water contaminant capture. J Mater Chem A 7:2507-2512

27. Slater AG, Cooper Al (2015) Porous materials. Function-led design of new porous materials. Science 348:988-999

28. Soler-Illia GJ, Azzaronic O (2011) Multifunctional hybrids by combining ordered mesoporous materials and macromolecular building blocks. Chem Soc Rev 40:1107-1150

29. Thomas A (2010) Functional materials: from hard to soft porous frameworks. Angew Chem Int Ed 49:8328-8344

30. Ben T, Ren H, Ma S, Cao D, Lan J, Jing X, Wang W, Xu J, Deng F, Simmons JM, Qiu S, Zhu G (2009) Targeted synthesis of a porous aromatic framework with high stability and exceptionally high surface area. Angew Chem Int Ed 48:9457-9460

31. Humbeck JFV, McDonald TM, Jing X, Wiers BM, Zhu G, Long JR (2014) Ammonia capture in porous organic polymers densely functionalized with bronsted acid groups. J Am Chem Soc 136:2432-2440

32. Garibay SJ, Weston MH, Mondloch JE, Colon YJ, Farha OK, Hupp JT, Nguyen ST (2013) Accessing functionalized porous aromatic frameworks (PAFs) through a de novo approach. CrystEngComm 15:1515-1519

33. Tian Y, Song J, Zhu Y, Zhao H, Muhammad F, Ma T, Chen M, Zhu G (2019) Understanding the desulphurization process in an ionic porous aromatic framework. Chem Sci 10:606-613

34. Zhang S, Li J, Du D, Qiu J, Li S, He W, Su Z, Lan Y (2015) A multifunctional microporous anionic metal-organic framework for column-chromatographic dye separation and selective detection and adsorption of $\mathrm{Cr}^{3+}$. J Mater Chem A 3:23426-23434

35. Zhu Z, Bai Y, Zhang L, Sun D, Fang J, Zhu S (2014) Two nanocage anionic metal-organic frameworks with rht topology and $\left\{\left[\mathrm{M}(\mathrm{H} 2 \mathrm{O})_{6}\right]_{6}\right\}^{12+}$ charge aggregation for rapid and selective adsorption of cationic dyes. Chem Commun 50:14674-14677

36. Ma H, Ren H, Zou X, Sun F, Yan Z, Cai K, Wang D, Zhu G (2013) Novel lithium-loaded porous aromatic framework for efficient $\mathrm{CO}_{2}$ and $\mathrm{H}_{2}$ uptake. J Mater Chem A 1:752-758

37. Ma H, Ren H, Zou X, Meng S, Sun F, Zhu G (2014) Post-metalation of porous aromatic frameworks for highly efficient carbon capture from $\mathrm{CO}_{2}+\mathrm{N}_{2}$ and $\mathrm{CH}_{4}+\mathrm{N}_{2}$ mixtures. Polym Chem 5:144-152

38. Sun J, Jing L, Tian Y, Sun F, Chen P, Zhu G (2018) Task-specific design of a hierarchical porous aromatic framework as an ultrastable platform for large-sized catalytic active site binding. Chem Commun 54:1603-1606

39. Li H, Liu Y, Liu J, Liu Z (2011) A Wulff-type boronate for boronate affinity capture of cis-diol compounds at medium acidic pH condition. Chem Commun 47:8169-8171

40. Zhu L, Shabbir SH, Gray M, Lynch VM, Sorey S, Anslyn EV (2006) A structural investigation of the N-B interaction in an o- $(\mathrm{N}$, $\mathrm{N}$-dialkylaminomethyl)arylboronate system. J Am Chem Soc 128:1222-1232

41. Chen D, Wang L, Ma Y, Yang W (2016) Super-adsorbent material based on functional polymer particles with a multilevel porous structure. NPG Asia Mater 8:e301-e309

42. Ma J, Yu F, Zhou L, Jin L, Yang M, Luan J, Tang Y, Fan H, Yuan Z, Chen J (2012) Enhanced adsorptive removal of methyl orange and methylene blue from aqueous solution by alkali-activated multiwalled carbon nanotubes. ACS Appl Mater Interfaces 4:5749-5760

43. Zhang $X$, Liu D, Yang L, Zhou L, You T (2015) Self-assembled three-dimensional graphene-based materials for dye adsorption and catalysis. J Mater Chem A 3:10031-10037

44. Shi $B$, Guan $H$, Shangguan $L$, Wang $H$, Xia D, Kong $X$, Huang $F$ (2017) A pillar[5]arene-based 3D network polymer for rapid removal of organic micropollutants from water. J Mater Chem A 5:24217-24222

Publisher's Note Springer Nature remains neutral with regard to jurisdictional claims in published maps and institutional affiliations. 